\title{
Adventures with Oxides: Utilizing Commercial and Internal Reference Materials for Geological and Materials Science Samples
}

\author{
Katherine Crispin \\ Pennsylvania State University, University Park, Pennsylvania, United States
}

Traditional mineral analysis relies on stoichiometric calculation of oxygen, which works well for many minerals but assumes that the mineral adheres to normal stoichiometry. This is not always a valid assumption. Although direct analysis of oxygen in the electron microprobe is possible, it remains challenging to ensure accuracy. Development of LDE (JEOL) and PC (CAMECA) crystals provide high count rates and high peak-to-background ratios, but traditional matrix corrections often give erroneous values (e.g. Armstrong, 1988). Over the past two decades, several papers have addressed these problems (e.g. Bastin and Heijligers, 1989), but it remains difficult to achieve reliable precision and repeatability. Adding to the complication is the wide variety of reference materials used in different labs; the same mineral can vary from different sources and even have inhomogeneity within an individual specimen. A few papers have attempted to benchmark reference materials for use in mineral analyses with some success (e.g. McGuire et al., 1992).

The situation for pure oxides is also difficult as matrix corrections do not calculate oxygen stoichiometry effectively, leading to the need for direct measurement of oxygen. Results are sensitive to the reference materials used in the analysis setup, resulting in vastly different (inaccurate) variation from the nominal composition (Table 1). Disparities in carbon coat thickness can also influence the absorption of O Ka Xrays, so it is critical to apply a carbon coat simultaneously to both the sample and reference.

With the advent of LaB-6 and field-emission microprobes, researchers are starting to examine small oxide inclusions in minerals and fine-scale ilmenite-magnetite intergrowths for thermobarometry, petrogenic indicators and partitioning coefficients. Another crucial application is in the ceramic industry, where highperformance piezoelectric single-crystal substrates, such as PMN-PT, are grown for various applications. The chemistry of these substrates is critical to the electromechanical coupling of devices, where even a small variance in the stoichiometry can cause performance issues. EPMA is utilized to capture the exact chemistry of both the starting materials and the finished crystals to determine uniformity between batches. Ferroelectric materials such as barium titanate (BT) can be modified to exhibit different properties with simple substitution of other cations into the material. For example, substitution of Sr shifts the Curie temperature while retaining permittivity. Cutting-edge unique optical glasses are also highly dependent on the proper chemistry dictating their properties. In each of these applications, it becomes important to have confidence in the exact chemistry determined by EPMA.

This study examines the complexity and challenge of choosing the correct reference materials to ensure accuracy, precision and repeatability. A wide range of reference materials are sourced from both commercial entities, such as Astimex, and trusted microprobe community sources, such as the Smithsonian. For some applications, internal reference standards are used to provide a baseline for comparison, especially in the ceramic community where they have a batch that performs to their needs and desire to see future batches match the performance. It is not ideal to use their internal standard for all analyses in the future, so this study also addresses benchmarking external standards to give the most consistent results. 


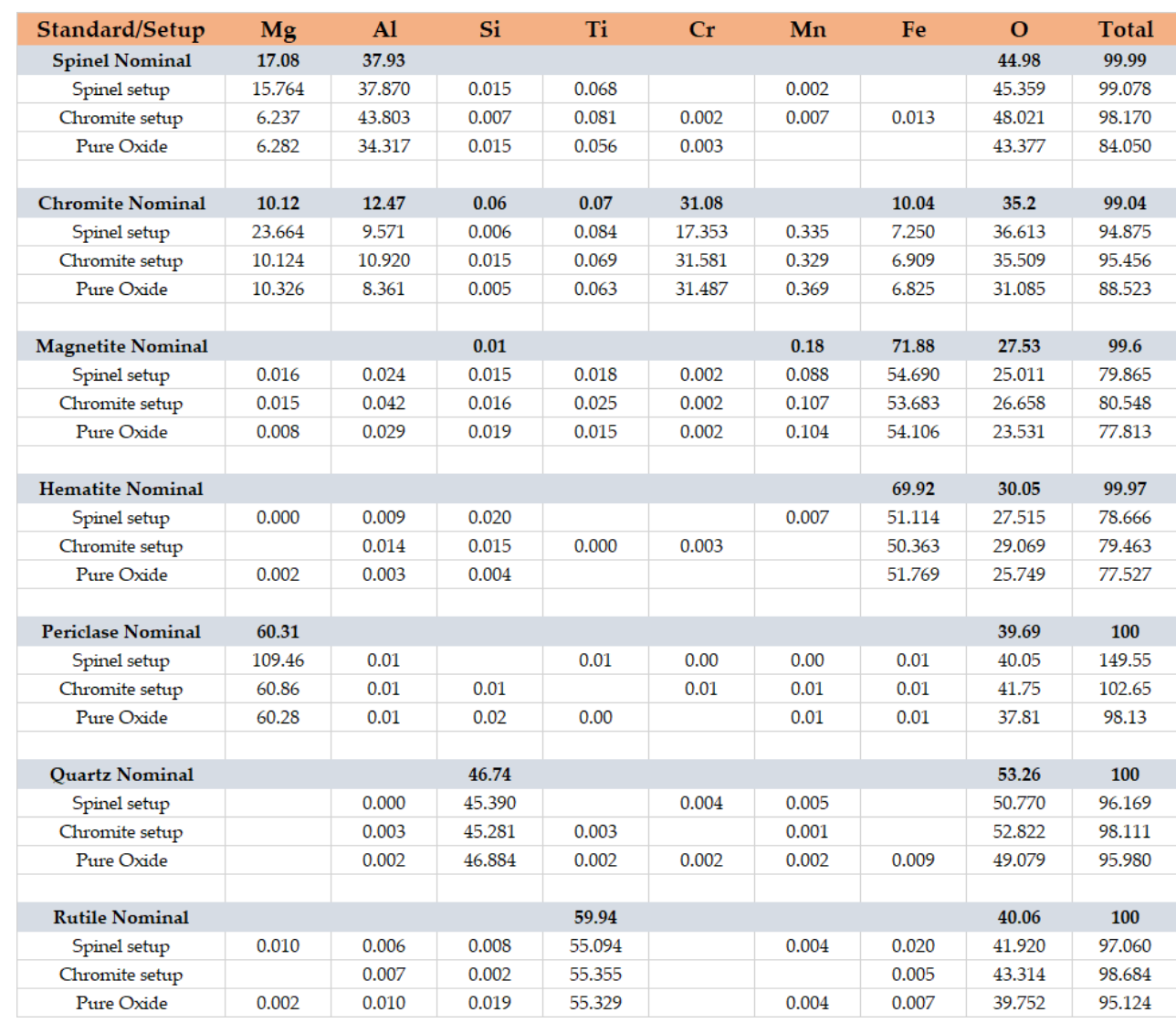

Figure 1. Table 1: Comparison of various oxide setups to nominal compositions of reference materials. [Spinel setup: $\mathrm{Mg}, \mathrm{Al}, \mathrm{O}$ on spinel; $\mathrm{Si}, \mathrm{Ca}, \mathrm{Cr}$ on pyrope; $\mathrm{Ti}$ on rutile; $\mathrm{Mn}$ on almandine; $\mathrm{Fe}$ on magnetite][Chromite setup: $\mathrm{Mg}, \mathrm{Al}, \mathrm{Cr}, \mathrm{O}$ on chromite; $\mathrm{Si}, \mathrm{Ca}$ on pyrope; $\mathrm{Ti}$ on rutile; $\mathrm{Mn}$ on almandine; Fe on magnetite][Pure oxide setup: $\mathrm{Mg}$ on periclase; $\mathrm{Al}$ on corundum; $\mathrm{Si}$ on quartz; $\mathrm{Ca}$ on sphene; $\mathrm{Ti}, \mathrm{O}$ on rutile; $\mathrm{Cr}$ on $\mathrm{Cr} 2 \mathrm{O} 3$; $\mathrm{Mn}$ on $\mathrm{Mn}$ metal; $\mathrm{Fe}$ on magnetite].

References

Armstrong, JT (1988) in Microbeam Analysis, DE Newbury, ed., p 301-304.

Bastin, FC and Heijligers, HJM (1989), in Microbeam Analysis, PE Russell, ed., p201-210.

McGuire, AV, Francis, CA, and Dyar, MD (1992), Am Min, vol 77, p 1087-1091. 